\title{
Factors Indicating Surgical Excision in Classical Type of Lobular Neoplasia of the Breast
}

\author{
Constanze Elfgen ${ }^{a, b} \quad$ Christoph Tausch ${ }^{a} \quad$ Ann-Katrin Rodewald ${ }^{c} \quad$ Uwe Güth $^{a, d}$ \\ Christoph Rageth $^{\text {e }}$ Vesna Bjelic-Radisic ${ }^{b, f}$ Markus Fleisch $^{b, f}$ Claudia Kurtz $^{g}$ \\ Jesus Gonzalez Diaz ${ }^{\text {h } \quad \text { Zsuzsanna Vargac }}$ \\ aBreast Center Zurich, Zurich, Switzerland; bUniversity of Witten-Herdecke, Witten, Germany; ' Institute of Pathology \\ and Molecular Pathology, University Hospital Zurich, Zurich, Switzerland; 'Faculty of Medicine, University of Basel, \\ Basel, Switzerland; 'Department of Gynecology and Obstetrics, Breast Center, Hôpitaux Universitaires de Genève, \\ Geneva, Switzerland; IInstitute of Gynecology and Obstetrics, University Hospital Wuppertal, Wuppertal, Germany; \\ gDepartment of Radiology and Nuclear Medicine, Kantonsspital Luzern, Lucerne, Switzerland; hFaculty of Medicine, \\ University of Zurich, Zurich, Switzerland
}

\section{Keywords \\ Lobular neoplasia - Lobular carcinoma in situ · Atypical lobular hyperplasia · Core needle biopsy · Vacuum-assisted biopsy · B3 lesion · High-risk lesion}

\begin{abstract}
Purpose: Classical type of lobular neoplasia (LN) encompassing both atypical lobular hyperplasia and classical lobular carcinoma in situ of the breast is a lesion with uncertain malignant potential and has been the topic of several studies with conflicting outcome results. The aim of our study was to clarify outcome-relevant factors and treatment options of classical LN. Methods: We performed a pathological re-evaluation of the preoperative biopsy specimens and a retrospective clinical and radiological data analysis of 160 patients with LN from the Breast Center Zurich. Open surgery was performed in 65 patients, vacuum-assisted biopsy (VAB) in 79 patients, and surveillance after breast core needle biopsy (CNB) in 16 patients. Results: The upgrade rate into ductal carcinoma in situ/invasive cancer was the highest in case of imaging/histology discordance (40\%). If the number of foci in the biopsy specimen was $\geq 3$, the upgrade rate in the consecutive surgical specimens was increased ( $p=0.01$ ). The association of classical LN with histological microcalcifi-
\end{abstract}

cation correlated with shortened disease-free survival ( $p<$ 0.01 ), whereas other factors showed no impact on follow-up. Conclusions: Surveillance or subsequent VAB after CNB of LN is sufficient in most cases. Careful consideration of individual radiological and histological factors is required to identify patients with a high risk of upgrade into malignancy. In those cases, surgical excision is indicated.

$$
\begin{aligned}
& \text { (c) } 2021 \text { The Author(s) } \\
& \text { Published by S. Karger AG, Basel }
\end{aligned}
$$

\section{Introduction}

Early detection of breast cancer by clinical imaging has been established in many countries [1]. Approximately $5-15 \%$ of screen-detected abnormalities include lesions with uncertain malignant potential (B3), of which classical lobular neoplasia (LN), encompassing both atypical lobular hyperplasia and classical lobular carcinoma in situ, is represented in 10-20\% [2-4]. Since the classical type of LN was first described, its diagnosis and treatment recommendations have undergone some fundamental changes [5]. Until today, conflicting data can put patient, radiologist, and surgeon in the uncomfortable position of having no strong management recommendation [6]. Open surgical excision of LN has
(C) 2021 The Author(s)

Published by S. Karger AG, Basel

This is an Open Access article licensed under the Creative Common Attribution-NonCommercial-4.0 International License (CC BY-NC) (http://www.karger.com/Services/OpenAccessLicense), applicable to the online version of the article only. Usage and distribution for commercial purposes requires written permission.
Correspondence to:

Constanze Elfgen, c.elfgen @ brust-zentrum.ch 
been the standard over decades [7]. Within the last years, there has been a trend towards minimally invasive management with vacuum-assisted biopsy (VAB) and frequent surveillance [8]. However, crucial points remain unclear. First, the diagnosis of LN has been considered "incidental," as there seem to be no typical patterns for this lesion. On the other hand, microcalcifications on mammogram are described as concordant and "typical" findings of LN [6]. Second, upgrade rates into ductal carcinoma in situ (DCIS) or invasive cancer show a tremendous variety from 4 to $44 \%$ within the current literature [9-12], which is also true for the follow-up outcome. The risk of developing breast cancer is increased up to four times $[9,13]$. Finally, discordance of imaging findings and histopathological diagnosis of $\mathrm{LN}$ was considered in a limited number of studies [12, 14-17]. It remains unclear whether there is an alternative option to open surgery in case of discordance. Obvious differences in designs in the cited studies and the expected connection between clinical imaging, diagnostic method, histopathological characters, and outcome of LN have not been delivered for an adequate number of patients so far.

The purpose of the study was to explore outcome-relevant imaging and histological factors to facilitate the decision-making process for patients with the diagnosis of LN in biopsy specimen. Endpoints were upgrade rate into DCIS/invasive cancer and disease-free follow-up. We assessed imaging features, histopathological features, concordance of these findings, and further treatment.

\section{Methods}

\section{Case Selection}

The data of 201 patients with biopsy-detected pure classical LN were derived from the institutional database of the Breast Center Zurich between 2008 and 2018. Medical records were reviewed for patients' personal data, diagnosis, and treatment. After a careful histopathological review of all paraffin-embedded breast biopsy specimens by an advanced fellow resident (A.-K.R.) and a breast pathologist (Z.V.), 41 patients were excluded from the analysis due to the coexistence of invasive carcinoma or DCIS in the biopsy specimens $(n=6)$, coexistence of other B3 lesions $(n=32)$, or the presence of pleomorphic LN $(n=3)$, which corresponds to a B5 lesion [18].

\section{Clinical Imaging and Biopsy Technique}

All patients received clinical breast imaging with standardized mammogram and ultrasound. Additional MRI was performed in 37 cases. Lesions were evaluated by trained breast radiologists and recorded by their type, BI-RADS ${ }^{\circledR}$ classification, and size (if available) [19]. In sonographically evident lesions, ultrasound-guided core needle biopsy (CNB) was performed with a 14-G needle (Tru$\left.\mathrm{Cut}^{\circledR}\right)$ and a minimum of three cores per lesion. In mammographically evident but sonographically occult lesions, stereotactic VAB was performed with an 11-G or 7-G needle and a minimum of six cores per lesion.

\section{Histopathological Review}

The formalin-fixed, paraffin-embedded biopsy specimens were processed according to the standardized protocols of the Department of Pathology and Molecular Pathology, University Hospital Zurich, Switzerland. The following points were considered in the analysis: (1) histological diagnosis of classical LN encompassing both lobular hyperplasia and classical lobular carcinoma in situ, (2) the presence of associated calcification, and (3) the number of LN foci in the biopsy cylinders. Additional immunohistochemistry reactions (such as E-cadherin loss and in most cases also cytoplasmic catenin p120 stains) further confirmed lobular differentiation and excluded ductal proliferation such as usual ductal hyperplasia or adenosis.

\section{Treatment Decision}

Discordance between radiological findings and histology of LN was defined as as BI-RADS ${ }^{\circledR} 5$ (>95\% malignancy) classification in the mammogram and/or ultrasound and/or MRI, or BI-RADS ${ }^{\circledR} 4$ (20-40\% malignancy) lesions, in which the histopathology of LN or coincidental benign findings did not correspond with the clinical imaging. All cases of discordant findings and most cases with concordant findings were discussed in the multidisciplinary preoperative tumor board of our breast center, which gave a consent recommendation for further treatment, including surgical excision, $\mathrm{VAB}$ (if the initial diagnosis was set by $\mathrm{CNB}$ ), or surveillance.

\section{Statistics}

For the descriptive analysis, mean (standard deviation) or median were used for continuous variables, and number and percentage were used for categorical variables. Disease-free survival was visualized with Kaplan-Meier plots of survival probability. $\chi^{2}$ tests were performed ( $p$ value for significance $<0.05$ ). All analyses were performed in the $\mathrm{R}$ programing language.

\section{Results}

Overall, 160 patients with classical LN were included in the study (Table 1). The mean age was 56.9 years; the main reason for initial presentation at the breast center was screening or follow-up $(n=77$ [48.1\%] and $n=45$ [28.1\%], respectively).

\section{Histopathological Review}

Most specimens contained one focus of LN (119 of 160 cases, 74.4\%) (Fig. 1). With a higher number of foci, the risk of upgrading also increased $(p=0.011)$ (Table 1$)$. Due to the larger sample volume of biopsy specimens, multiple $\mathrm{LN}$ foci were more often observed in VAB than in CNB (10 of 53 [18.9\%] vs. 13 of 107 [12.1\%]). Histopathological association of classical LN with microcalcification was observed in $11.9 \%$ (19 of 160) (Table 1; Fig. 2), which however showed no significant association with upgrade, but showed a significant correlation with disease-free survival in the follow-up outcome $(p=0.001)$ (Fig. 3).

\section{Clinical Imaging and Discordant Findings}

The average lesion size was $13.6 \mathrm{~mm}$ in mammogram and $13.3 \mathrm{~mm}$ in ultrasound. Microcalcification and mass 
Table 1. Clinical data, imaging, and histopathology of patients with LN who had an upgrade/no upgrade in final histology

\begin{tabular}{|c|c|c|c|c|}
\hline & Overall & $\begin{array}{l}\text { Upgrade in } \\
\text { final histology }\end{array}$ & $\begin{array}{l}\text { No upgrade in } \\
\text { final histology }\end{array}$ & $p$ value \\
\hline$n(\%)$ & $160(100 \%)$ & $17(10.6 \%)$ & $143(89.4 \%)$ & \\
\hline Mean age, years (SD) & $56.9(11.7)$ & $60.1(11.7)$ & $56.5(11.7)$ & 0.248 \\
\hline \multicolumn{4}{|l|}{ Risk of hereditary breast cancer } & 0.530 \\
\hline Yes & $34(21.2 \%)$ & $2(5.9 \%)$ & $32(94.1 \%)$ & \\
\hline No/unknown & $126(78.8 \%)$ & $15(11.9 \%)$ & $111(88.1 \%)$ & \\
\hline \multicolumn{4}{|l|}{ Previous contralateral breast cancer } & 0.745 \\
\hline Yes & $31(19.4 \%)$ & $4(12.9 \%)$ & $27(87.1 \%)$ & \\
\hline No & $129(80.6 \%)$ & $13(10.1 \%)$ & $116(89.9 \%)$ & \\
\hline \multicolumn{4}{|l|}{ Diagnostic method } & 0.088 \\
\hline Tru-Cut ${ }^{\circledR}$ biopsy & $107(66.9 \%)$ & $15(14.0 \%)$ & $92(86.0 \%)$ & \\
\hline $\mathrm{VAB}$ & $53(33.1 \%)$ & $2(3.8 \%)$ & $51(96.2 \%)$ & \\
\hline \multicolumn{4}{|l|}{ Ultrasound classification according to BI-RADS ${ }^{\circledR}$} & 0.015 \\
\hline BI-RADS ${ }^{\circledR} 1$ & $6(3.8 \%)$ & 0 & $6(100 \%)$ & \\
\hline BI-RADS $^{\circledR} 2$ & $37(23.6 \%)$ & $2(5.4 \%)$ & $35(94.6 \%)$ & \\
\hline BI-RADS $^{\circledR} 3$ & $73(46.5 \%)$ & $7(9.6 \%)$ & $66(90.4 \%)$ & \\
\hline BI-RADS $^{\circledR} 4$ & $37(23.6 \%)$ & $5(13.5 \%)$ & $32(86.5 \%)$ & \\
\hline BI-RADS $^{\circledR} 5$ & $4(2.6 \%)$ & $3(75.0 \%)$ & $1(25.0 \%)$ & \\
\hline BI-RADS ${ }^{\circledR} 0$ & $3(1.9 \%)$ & $1(33.3 \%)$ & $2(66.6 \%)$ & \\
\hline \multicolumn{4}{|l|}{ Type of ultrasound lesion } & 0.998 \\
\hline Mass & $94(76.4 \%)$ & $11(11.7 \%)$ & $83(88.3 \%)$ & \\
\hline Microcalcification & $2(1.6 \%)$ & 0 & $2(100 \%)$ & \\
\hline Architectural distortion & $19(15.4 \%)$ & $2(10.5 \%)$ & $17(89.5 \%)$ & \\
\hline Cyst & $8(6.5 \%)$ & $1(12.5 \%)$ & $7(87.5 \%)$ & \\
\hline Unknown & 37 & $3(8.1 \%)$ & $34(91.9 \%)$ & \\
\hline \multicolumn{4}{|l|}{ Breast density } & 0.808 \\
\hline ACR a & 0 & 0 & 0 & \\
\hline ACR b & $54(34.4 \%)$ & $7(13.0 \%)$ & $47(87.0 \%)$ & \\
\hline ACR c & $86(54.8 \%)$ & $9(10.5 \%)$ & $77(89.5 \%)$ & \\
\hline ACR d & $17(10.8 \%)$ & $1(5.9 \%)$ & $16(94.1 \%)$ & \\
\hline \multicolumn{4}{|l|}{ Mammogram classification according to BI-RADS ${ }^{\circledR}$} & 0.047 \\
\hline BI-RADS ${ }^{\circledR} 1$ & $1(0.7 \%)$ & 0 & $1(100 \%)$ & \\
\hline BI-RADS $^{\circledR} 2$ & $58(37.7 \%)$ & $5(8.6 \%)$ & $53(91.4 \%)$ & \\
\hline $\mathrm{BI}^{-\mathrm{RADS}^{\circledR} 3}$ & $36(23.4 \%)$ & $6(16.7 \%)$ & $30(83.3 \%)$ & \\
\hline BI-RADS ${ }^{\circledR} 4$ & $52(33.8 \%)$ & $3(5.8 \%)$ & $49(94.2 \%)$ & \\
\hline BI-RADS $^{\circledR} 5$ & $7(4.6 \%)$ & $3(42.9 \%)$ & $4(57.1 \%)$ & \\
\hline BI-RADS ${ }^{\circledR} 0$ & $6(3.8 \%)$ & 0 & $6(100 \%)$ & \\
\hline \multicolumn{4}{|l|}{ Type of mammographic lesion } & 0.770 \\
\hline Mass & $39(24.4 \%)$ & $3(7.7 \%)$ & $36(92.3 \%)$ & \\
\hline Microcalcification & $62(38.8 \%)$ & $7(11.3 \%)$ & $55(88.7 \%)$ & \\
\hline Architectural distortion & $13(8.1 \%)$ & $3(23.1 \%)$ & $10(76.9 \%)$ & \\
\hline Cyst & $19(11.9 \%)$ & $4(21.1 \%)$ & $15(78.9 \%)$ & \\
\hline Unknown & $27(16.9 \%)$ & $5(18.5 \%)$ & $22(81.5 \%)$ & \\
\hline \multicolumn{4}{|l|}{ Discordance } & $<0.001$ \\
\hline Yes & $20(12.5 \%)$ & $8(40.0 \%)$ & $12(60.0 \%)$ & \\
\hline No & $140(87.5 \%)$ & $9(6.4 \%)$ & $131(93.6 \%)$ & \\
\hline \multicolumn{4}{|l|}{ Number of histological LN foci in biopsy specimens } & 0.011 \\
\hline 1 & $119(74.4 \%)$ & $9(7.6 \%)$ & $110(92.4 \%)$ & \\
\hline 2 & $18(11.2 \%)$ & $2(11.1 \%)$ & $16(88.9 \%)$ & \\
\hline$\geq 3$ & $23(14.4 \%)$ & $6(26.0 \%)$ & $17(73.9 \%)$ & \\
\hline \multicolumn{4}{|l|}{$\begin{array}{l}\text { LN associated with microcalcification in histopathology } \\
\text { of biopsy specimen }\end{array}$} & 0.123 \\
\hline Yes & $19(11.9 \%)$ & $4(21.1 \%)$ & $15(78.9 \%)$ & \\
\hline No & $141(88.1 \%)$ & $13(9.2 \%)$ & $128(90.8 \%)$ & \\
\hline
\end{tabular}

ACR, American College of Radiology; LN, lobular neoplasia; VAB, vacuum-assisted biopsy. 
Fig. 1. Histological appearance of classical LN. Vacuum-assisted biopsy demonstrates one focus of classical LN (type lobular carcinoma in situ, white arrow). There is an imaging relevant calcification in LN, shown also in inset (white arrow). The calcification is in the middle of discohesive lobular cells filling the complete acini. All images hematoxylin \& eosin stain. LN, lobular neoplasia.

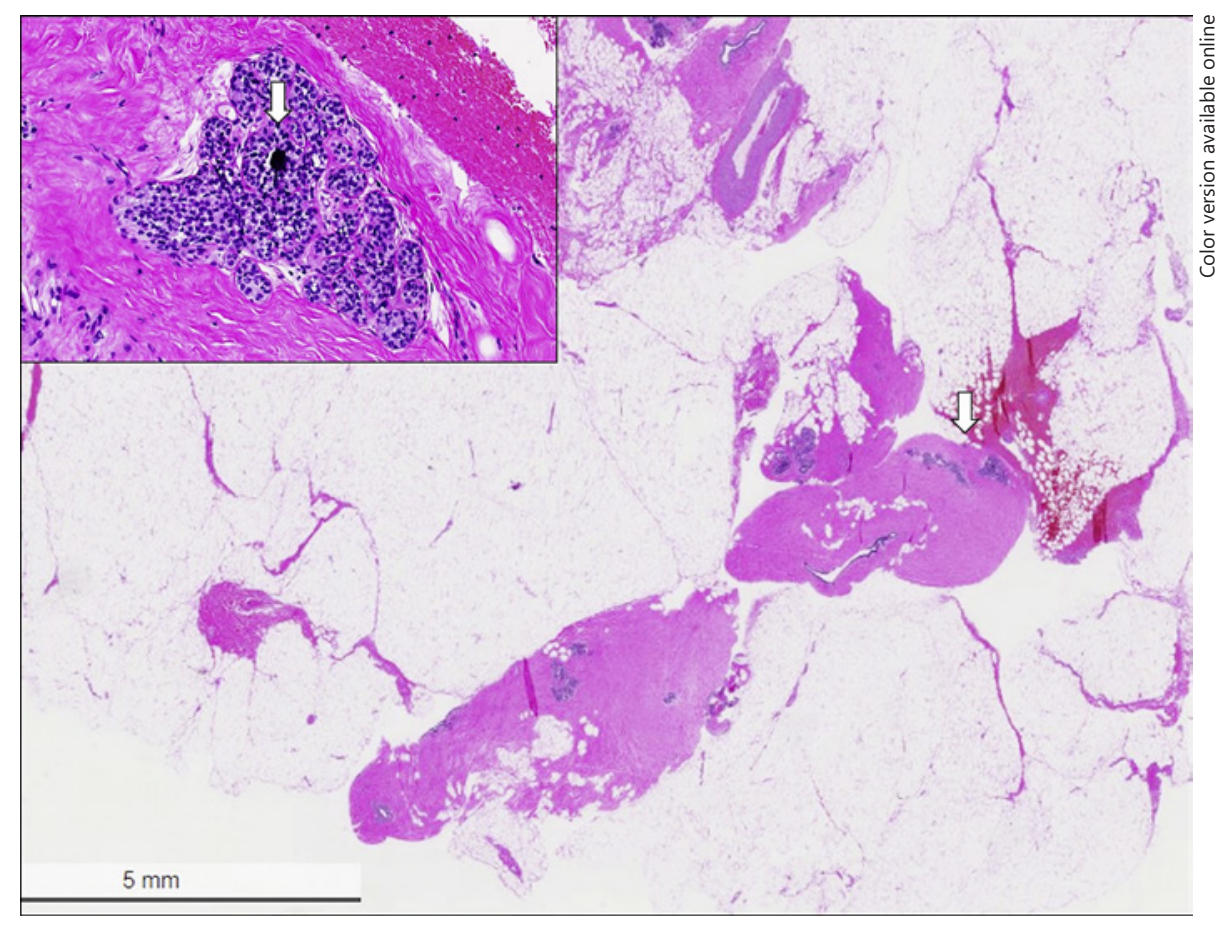

Fig. 2. Histological appearance of classical LN. Vacuum-assisted biopsy showing four foci of classical LN (type atypical lobular hyperplasia, white arrows). There is only minimal calcification in LN. Imaging relevant microcalcification is seen in columnar cell hyperplasia and flat epithelial atypia (back arrows) Upper Inset: large calcification is seen in a duct in the adjacent vicinity of columnar cell lesions. Lower inset: higher magnification of the atypical lobular hyperplasia shows discohesive lobular cells in a pagetoid spread. All images hematoxylin \& eosin stain. LN, lobular neoplasia.

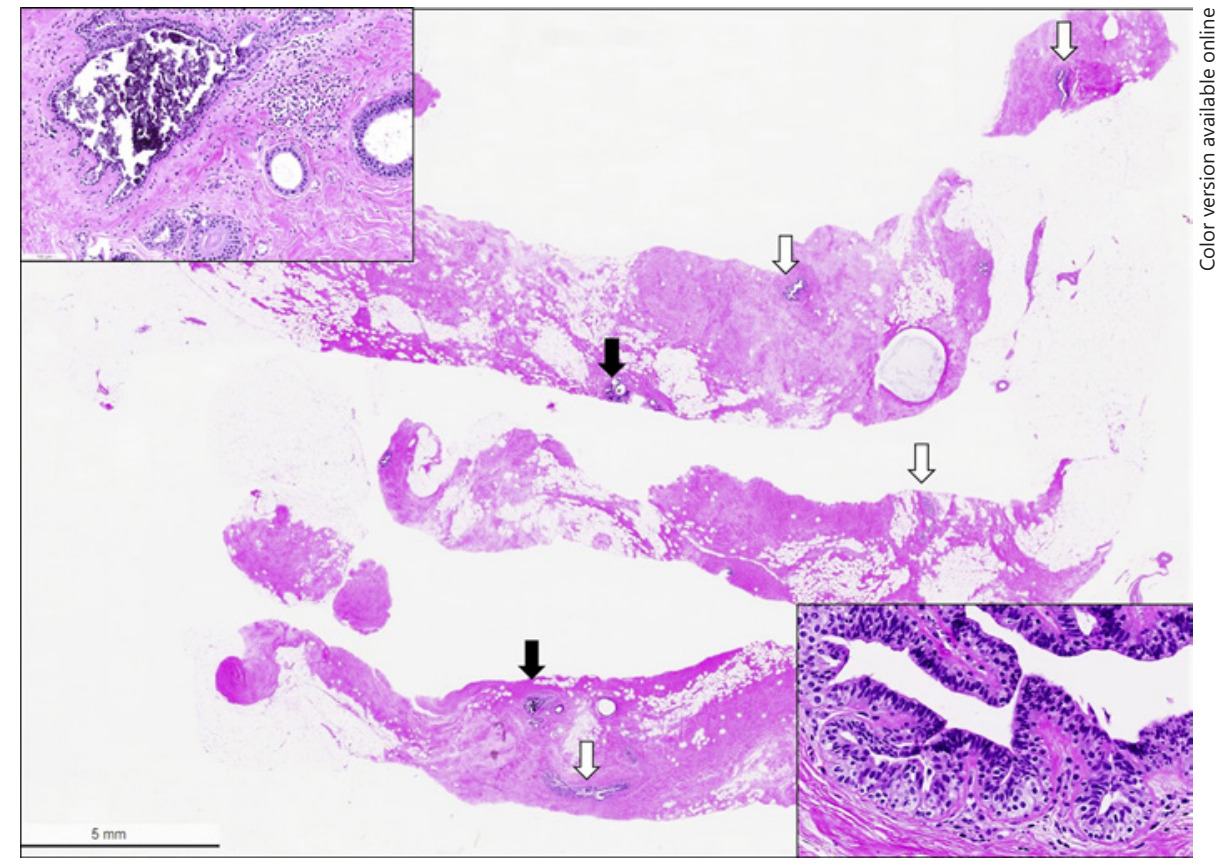

( $n=62$ [38.8\%] and $n=39$ [24.4\%], respectively) were the main lesion characteristics in mammogram; mass and architectural distortion were the central findings in ultrasound ( $n=94$ [58.8\%] and $n=19$ [11.9\%], respectively) (Table 1). Most of the patients underwent biopsy due to suspicious findings in mammogram (BI-RADS ${ }^{\circledR} 4$ and 5 in 59 cases, 36.9\%) and/or ultrasound (BI-RADS ${ }^{\circledR} 4$ and 5 in 41 cases, 25.6\%). In the remaining cases, biopsy was performed due to BI-RADS ${ }^{\circledR} 3$ findings despite a low likelihood of malignancy $(\leq 2 \%)[19,20]$. Additional MRI was performed in 37 cases (23.1\%); a BI-RADS 4 and 5 classification was given in 19 cases (51.4\%). Discordant findings of clinical imaging and histopathological diagnosis were reported in 20 cases (12.5\%), most of which occurred after ultrasound-guided CNB had been performed $(n=19)$. 


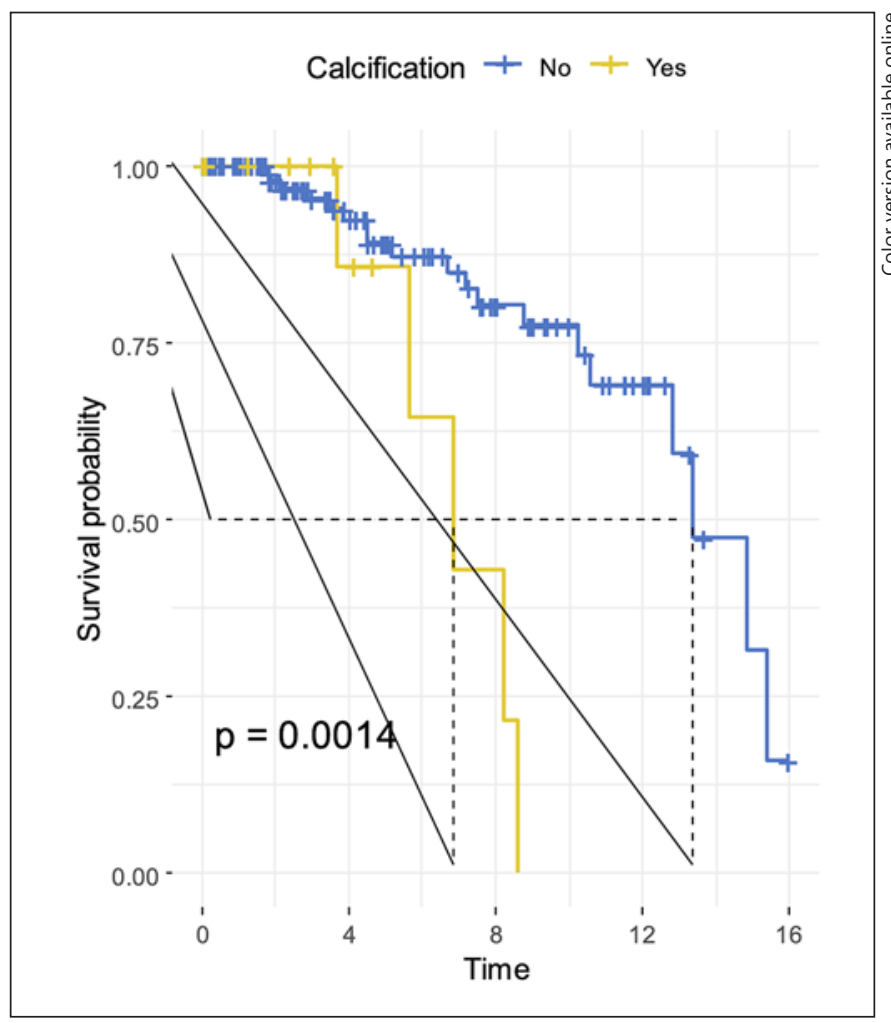

Fig. 3. Disease-free follow-up of patients with LN pathologically associated with calcifications versus no association. LN, lobular neoplasia.

\section{Further Diagnostic/Treatment and Upgrade Rate}

The initial diagnosis of $\mathrm{LN}$ was given after CNB in 107 cases and after $\mathrm{VAB}$ in 53 cases. Treatment decisions were made in the interdisciplinary tumor board of our breast center based on clinical, radiological, and pathological aspects. Out of 107 patients diagnosed by CNB, 53 (49.5\%) received a subsequent surgical excision, 39 (36.4\%) received a secondary VAB, and 16 (14.9\%) underwent surveillance.

Patients with initial VAB $(n=53)$ received a surgical excision in 12 cases (22.6\%). Surgical excision revealed DCIS/invasive cancer in 2 cases after VAB $(16.7 \%$ of 53 patients) and in 13 cases after CNB (24.5\% of 107 patients). Secondary VAB led to an upgrade in 2 cases after CNB (1.9\% of 107 patients). Patients without further invasive diagnostic after initial LN diagnosis (16 [14.9\%] of 107 cases after CNB and 41 [77.4\%] of 53 cases after VAB) underwent surveillance by annual follow-up with mammogram and ultrasound. In most cases of discordant findings $(n=20)$, open surgery was performed $(n=14$; $70 \%)$, resulting in an upgrade in 6 cases (42.9\%). Further sampling with $\mathrm{VAB}$ after initial CNB was performed in 2 cases (10\%; upgrade in both cases; $100 \%)$, and observation in 4 cases (20\%; no event in follow-up). The risk of upgrade in the subsequent open surgery increased with the number of foci in the biopsy specimen (Table 1), whereas the association with microcalcification had no impact.

In most upgraded cases, we observed invasive lobular carcinoma (ILC) $(n=9 ; 52.9 \%)$ versus $n=6(35.3 \%)$ of breast cancer of no special type (NST) and $n=2(11.8 \%)$ of DCIS.

\section{Follow-Up Outcome}

Patients with upgrade into DCIS/invasive cancer $(n=$ $17 ; 10.6 \%)$ were excluded from the follow-up analysis. The median follow-up was 45 months, the median disease-free survival in the study population was 13.3 years. During follow-up, we observed events in 24 cases (16.8\%), with recurrent B3 lesion in 7 cases. Malignancy occurred in 17 patients $(11.9 \%$ of 143$)$, in which the ipsilateral breast was affected in 11 patients, the contralateral breast in 4 patients, and bilateral in 2 cases. Patients with discordant findings but without final histopathological upgrade did not differ in long-term outcome compared to patients with concordant findings. Long-term follow-up outcome was not improved in patients who underwent open surgery with a DCIS/invasive cancer rate of $14 \%$ (7 of 50) versus $7.1 \%$ (4 of 56) in patients with surveillance and $16.2 \%$ (6 of 37 ) in patients with VAB (either primary or secondary). If LN was histologically associated with calcification, the disease-free survival was significantly lower than in patients who had LN without associated calcification (Fig. 3).

\section{Discussion}

\section{Radiological Factors}

According to previous studies, we did not observe a typical imaging pattern of LN [21]. A histopathological association with microcalcification was detected in only 19 of 61 cases that presented with microcalcification as the leading lesion in the mammogram. Most microcalcifications in mammogram or ultrasound were caused by coexisting benign lesions such as sclerosing adenosis, and the presence of microcalcification in clinical imaging was not associated with upgrade or poorer outcome. Considering that microcalcifications are the only potential radiological-pathological correlation that could be characteristic for LN, $88.1 \%$ of LN in our study group were incidental findings [21]. Likewise, mass as a leading lesion in ultrasound or mammogram in most cases was based on coincidental benign changes such as fibroadenoma, pseudoangiomatous stromal hyperplasia, or fibrocystic changes and was regarded as being concordant to the imaging findings [22]. However, in a study group exclusively screened with mammogram, the number of histopathological association with microcalcification can be higher [6]. About $20 \%$ of the patients underwent 


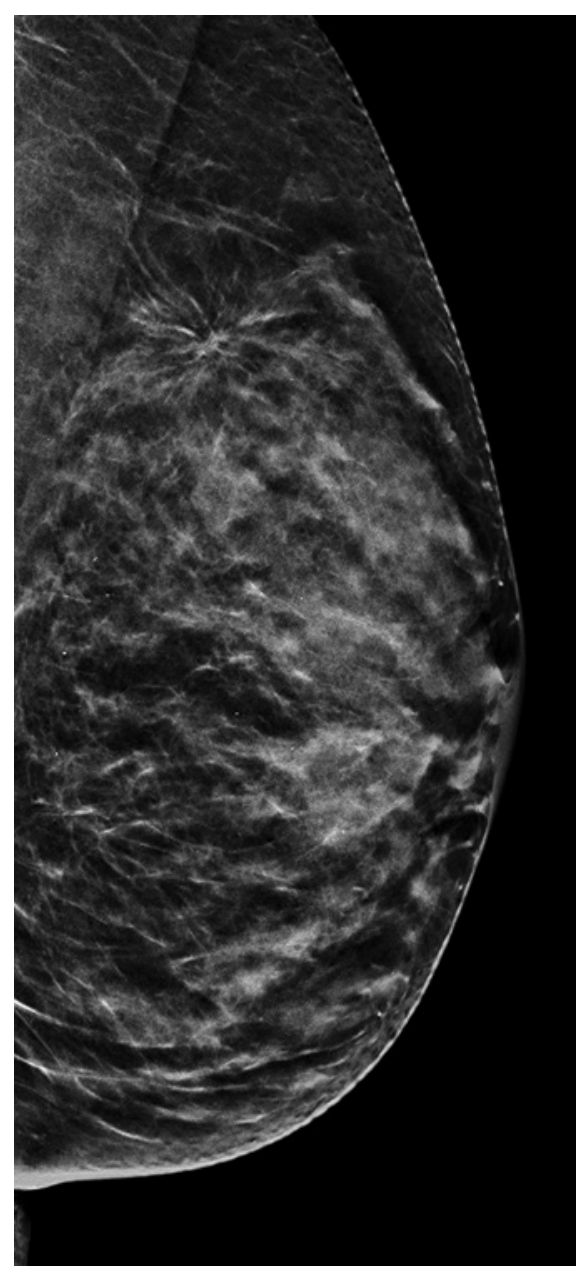

Fig. 4. Discordance in clinical imaging and histopathological diagnosis. LN does not explain the architectural distortion on mammogram (BI-RADS 5), even though ultrasound did not show a suspicious lesion (BI-RADS 2). LN, lobular neoplasia.

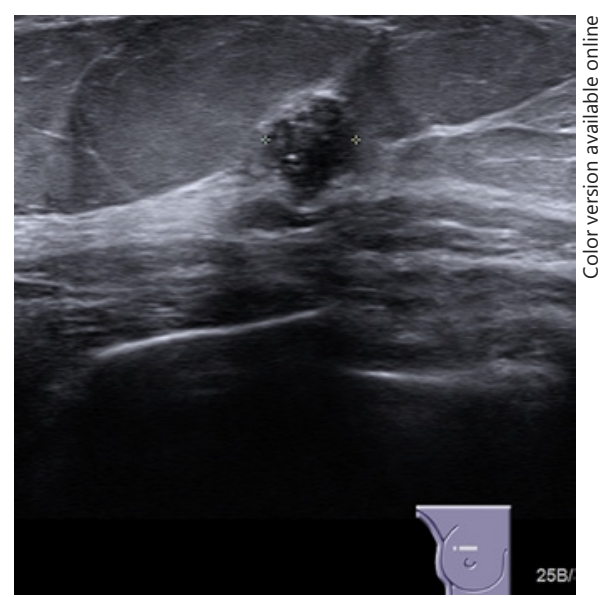

Fig. 5. Ultrasound lesion classified as $\operatorname{BIRADS}^{\circledR} 3$ with $\mathrm{LN}$ in the biopsy specimen but missing a histological diagnosis that could explain a mass in clinical imaging. Subsequent surgery revealed an invasive lobular cancer. LN, lobular neoplasia. an additional MRI. Due to this limited number, a statistically relevant conclusion is not possible and was not the aim of the study. However, as MRI showed a lesion leading to the diagnosis of LN in 8 cases, we can emphasize the current practice of additional MRI in selected patients.

\section{Radiological-Pathological Correlation}

Discordance of clinical imaging and histopathology was observed in $12.5 \%$, suggesting an inadequate sampling of the suspicious lesion (Fig. 4). Not surprisingly, discordance was more frequent in $\mathrm{CNB}$, which provides less biopsy material than VAB. However, the underestimation rate of $\mathrm{B} 3$ lesions regarding the biopsy technique has rarely been investigated so far [23]. We observed an upgrade rate of $42.9 \%$ in case of discordance, whereas in patients without discordance the upgrade rate after open surgery was $19.5 \%$. This number also seems high at first glance [10-13], but one has to consider that a notable number of patients $(24.4 \%)$ of our study group received a further sampling with $\mathrm{VAB}$ after $\mathrm{LN}$ had been found in CNB, and open surgery was avoided in nearly all of these cases. Even more, onethird of all patients underwent no further invasive diagnostics except for annual surveillance, a decision confirmed by an acceptable follow-up outcome as the incidence of DCIS/invasive cancer was $7.1 \%$ during the follow-up period of 45 months (median). These results underline the benefit of re-evaluating clinical and pathological features in an interdisciplinary tumor board of a breast center [12, 14-17]. According to our knowledge, our study is the first that considers the individualized decision-making process regarding to the outcome of different treatment options in classical LN. The definition of radiological-pathological discordance depends on the physician's individual experience (Fig. 5). In 4 cases that were initially described as being discordant, no open surgery or further sampling was performed. In these cases, the tumor board-based review and discussion of clinical imaging and histopathology relativized "discordance." All 4 patients have been disease-free in the follow-up, which indicates that unnecessary patient anxiety as well as costs and risks of open surgery were justifiably avoided.

Open surgery was clearly less frequently indicated after $\mathrm{VAB}$ than after $\mathrm{CNB}$ because $\mathrm{VAB}$ provides a more valid diagnosis due to a higher quantity of biopsy specimen, which was confirmed by a lower upgrade rate of these cases [23]. Our data are concordant to those of earlier studies and emphasize the safety of the VAB technique [24]. However, the option of hand-held ultrasound-guided VAB in this context has hardly been reflected in the literature so far, but was considered in our study [8]. 


\section{Histopathological Factors}

The higher number of LN foci $(\geq 3)$ in the biopsy specimens was associated with a significantly higher number of upgrades in the surgical specimens $(p=0.01)$. In a recent publication by Holbrook et al. [17], quantification of the terminal duct lobular units involved does not predict a higher upgrade rate. However, an increased number of foci can be a risk factor for coexisting invasive carcinoma or DCIS not present in the preoperative breast biopsies independently from the LN's quantitative involvement of terminal duct lobular units. Our data suggest that in case of three or more histological foci of LN in a biopsy specimen, open surgery is indicated. Interestingly, disease-free survival was decreased if LN was histologically associated with calcification in our cohort. However, calcification-associated LN did not initially correlate with a higher upgrade rate. Therefore, the recommendation of open surgery in these cases might not be justified; instead, a close follow-up has to be emphasized. If microcalcifications in clinical imaging increase in the region of proofed LN, re-biopsy should be recommended. As the event numbers in pure cohort are low, this result should be interpreted with caution. Further studies are warranted to clarify the prognostic role of histopathological microcalcification in LN.

ILC was revealed in most cases of upgrading histopathology. However, NST and DCIS were present in 35.3\% and $11.8 \%$, respectively. In the current models of breast cancer pathogenesis, the development of ILC differs from NST [25]. On the other hand, coincidence of LN and DCIS is known, and a shift from NST towards ILC can be observed in mixed tumors [26]. It would be of great interest to observe whether an upgrade into NST and DCIS has to be regarded as a coincidence, probably based on mechanisms of a "sick lobule," or if a shift from LN to NST could also be plausible [27].

\section{Follow-Up Outcome}

LN has up to a four-fold increased risk of subsequent invasive breast cancer [13]. During a median follow-up of approximately 4 years, we observed occurrence of DCIS or invasive cancer in $11.9 \%$, most of which was in the ipsilateral breast, but only $3.5 \%$ in the same quadrant. However, LN increases the risk of breast cancer in both breasts, and our results are in line with studies showing a higher rate of ipsilateral cancer in the followup [28, 29]. Histologically microcalcification worsened the outcome, but our data showed no impact of initial clinical or radiological factors to the disease-free followup. This is also the case for the upgrade-relevant factors of radiological-pathological discordance and pathological number of foci in the initial biopsy specimen. Open surgery of classical LN did not improve the follow-up outcome.

\section{Strengths and Weaknesses}

For the time being, there are no guidelines for clinical practice in LN as the outcome results of numerous studies are contradictory [9-13]. The current expert-based consent trends towards less invasive treatment, but not without conflicts [8]. Our study is the first that considers the factors of diagnostic method, pathological factors, radiological-pathological correlation, and decision-making process in a large number of patients. Our study includes a retrospective data analysis with several potential confounders. Although our study has a higher case number and longer follow-up, the variance of performed treatments makes it less comparable to previous studies. However, this also reflects clinical practice as it is increasingly recommended. A careful histopathological review revealed coexisting B3 lesions of other categories. Excluding these cases offers more precise data about LN. However, we did not subcategorize LN into atypical lobular hyperplasia and lobular carcinoma in situ like other authors, though this is controversial in biopsy specimen.

\section{Conclusion}

LN of classical type is an incidental finding in most cases and is per se not an indication for further treatment. However, our results show that an increased number of LN foci in the preoperative breast biopsy showed a significant association with upgrade in the consecutive surgical excision, which should be considered in the interdisciplinary preoperative board and be an integral part of the histopathology report. The association of classical LN with histological microcalcification correlates with decreased disease-free survival. An interdisciplinary decision-making process is crucial to avoid missing a cancer, especially in case of radiological-pathological discordance. In case the initial diagnosis was set by $\mathrm{CNB}$, second-line $\mathrm{VAB}$ is a safe alternative to open surgery in most cases.

\section{Statement of Ethics}

The study was approved by the Cantonal Ethics Committee of Zurich, Switzerland (BASEC No. 219-00948) and was performed in accordance with the 1964 Helsinki declaration and its later amendments or comparable ethical standards. Written informed consent was obtained from all individual participants included in the study.

\section{Conflict of Interest Statement}

All authors declare that they have no conflict of interest. 


\section{Funding Sources}

There was no funding.

\section{References}

1 Altobelli E, Rapacchietta L, Angeletti PM, Barbante L, Profeta FV, Fagnano R. Breast cancer screening programmes across the WHO European region: differences among countries based on national income level. Int J Environ Res Public Health. 2017;14:452.

2 Rakha EA, Ellis IO. An overview of assessment of prognostic and predictive factors in breast cancer needle core biopsy specimens. J Clin Pathol. 2007;60:1300-6.

3 Houssami N, Ciatto S, Bilous M, Vezzosi V, Bianchi S. Borderline breast core needle histology: predictive values for malignancy in lesions of uncertain malignant potential (B3). Br J Cancer. 2007;96:1253-7.

4 Richter-Ehrenstein C, Maak K, Röger S, Ehrenstein $\mathrm{T}$. Lesions of "uncertain malignant potential" in the breast (B3) identified with mammography screening. BMC Cancer. 2018;18:829.

5 Foote FW, Stewart FW. Lobular carcinoma in situ: a rare form of mammary cancer. Am J Pathol. 1941;17:491-3.

6 Maxwell AJ, Clements K, Dodwell DJ, Evans AJ, Francis A, Hussain $M$, et al. The radiological features, diagnosis and management of screen-detected lobular neoplasia of the breast: findings from the Sloane Project. Breast. 2016;27:109-15.

7 Morrow M, Schnitt SJ, Norton L. Current management of lesions associated with an increased risk of breast cancer. Nat Rev Clin Oncol. 2015;12:227-38.

8 Rageth CJ, O’Flynn EAM, Pinker K, KubikHuch RA, Mundinger A, Decker T, et al. Second International Consensus Conference on lesions of uncertain malignant potential in the breast (B3 lesions). Breast Cancer Res Treat. 2019;174(2):279-96.

9 Renshaw AA, Gould EW. Long term clinical follow-up of atypical ductal hyperplasia and lobular carcinoma in situ in breast core needle biopsies. Pathology. 2016;48:25-9.

10 Lewis JL, Lee DY, Tartter PI. The significance of lobular carcinoma in situ and atypical lobular hyperplasia of the breast. Ann Surg Oncol. 2012;19:4124-8.

\section{Author Contributions}

All authors made substantial contributions to the conception and/or design of the study, and/or the acquisition of data, and/or the data analysis, and/or the interpretation of data.
11 Dillon MF, McDermott EW, Hill AD, O’Doherty A, O’Higgins N, Quinn CM. Predictive value of breast lesions of "uncertain malignant potential" and "suspicious for malignancy" determined by needle core biopsy. Ann Surg Oncol. 2007;14(2):704-11.

12 Schmidt H, Arditi B, Wooster M, Weltz C, Margolies L, Bleiweiss I, et al. Observation versus excision of lobular neoplasia on core needle biopsy of the breast. Breast Cancer Res Treat. 2018;168:649-54.

13 Wärnberg F, Yuen J, Holmberg L. Risk of subsequent invasive breast cancer after breast carcinoma in situ. Lancet. 2000;355:724-5.

14 Murray MP, Luedtke C, Liberman L, Nehhozina T, Akram M, Brogi E. Classic lobular carcinoma in situ and atypical lobular hyperplasia at percutaneous breast core biopsy: outcomes of prospective excision. Cancer. 2013;119:1073-9.

15 Amos B, Chetlen A, Williams N. Atypical lobular hyperplasia and lobular carcinoma in situ at core needle biopsy of the breast: an incidental finding or are there characteristic imaging findings? Breast Dis. 2016;36:5-14.

16 Atkins KA, Cohen MA, Nicholson B, Rao S. Atypical lobular hyperplasia and lobular carcinoma in situ at core breast biopsy: use of careful radiologic-pathologic correlation to recommend excision or observation. Radiology. 2013;269:340-7.

17 Holbrook AI, Hanley K, Jeffers C, Kang J, Cohen MA. Triaging atypical lobular hyperplasia and lobular carcinoma in situ on percutaneous core biopsy to surgery or observation: assiduous radiologic-pathologic correlation works, quantitating extent of disease does not. Arch Pathol Lab Med. 2019;143:621-7.

18 Middleton LP, Palacios DM, Bryant BR, Krebs P, Otis CN, Merino MJ. Pleomorphic lobular carcinoma: morphology, immunohistochemistry, and molecular analysis. Am J Surg Pathol. 2000;24:1650-6.

19 Balleyguier C, Ayadi S, Van Nguyen K, Vanel D, Dromain C, Sigal R. BIRADS classification in mammography. Eur J Radiol. 2007;61: 192-4.
20 Boyer B, Canale S, Arfi-Rouche J, Monzani Q, Khaled W, Balleyguier C. Variability and errors when applying the BIRADS mammography classification. Eur J Radiol. 2013;82:38897.

21 King TA, Reis-Filho JS. Lobular neoplasia. Surg Oncol Clin N Am. 2014;23:487-503.

22 Fives C, O’Neill CJ, Murphy R, Corrigan MA, O'Sullivan MJ, Feeley L, et al. When pathological and radiological correlation is achieved, excision of fibroadenoma with lobular neoplasia on core biopsy is not warranted. Breast. 2016;30:125-9.

23 Londero V, Zuiani C, Linda A, Battigelli L, Brondani G, Bazzocchi M. Borderline breast lesions: comparison of malignancy underestimation rates with 14-gauge core needle biopsy versus 11-gauge vacuum-assisted device. Eur Radiol. 2011;21:1200-6.

24 Batohi B, Fang C, Michell MJ, Morel J, Shah C, Wijesuriya S, et al. An audit of mammographic screen detected lesions of uncertain malignant potential (B3) diagnosed on initial image guided needle biopsy: how has our practice changed over 10 years? Clin Radiol. 2019;74:653.e19-25.

25 Simpson PT, Reis-Filho JS, Gale T, Lakhani SR. Molecular evolution of breast cancer. J Pathol. 2005;205:248-54.

26 Tot T. The theory of the sick breast lobe and the possible consequences. Int J Surg Pathol. 2007;15:369-75.

27 McCart Reed AE, Kutasovic JR, Nones K, Saunus JM, Da Silva L, Newell F, et al. Mixed ductal-lobular carcinomas: evidence for progression from ductal to lobular morphology. J Pathol. 2018;244:460-8.

28 Li CI, Malone KE, Saltzman BS, Daling JR. Risk of invasive breast carcinoma among women diagnosed with ductal carcinoma in situ and lobular carcinoma in situ, 19882001. Cancer. 2006;106:2104-12.

29 Sohn VY, Arthurs ZM, Kim FS, Brown TA. Lobular neoplasia: is surgical excision warranted? Am Surg. 2008;74:172-7. 